CAREER COLUMN 26 AUGUST 2020

\title{
How I managed my work and personal life as a sole parent during the pandemic
}

Staying connected with other single-parent academics through a Facebook group was one of four steps taken by Antica Culina to survive the lockdown.

\section{Antica Culina}

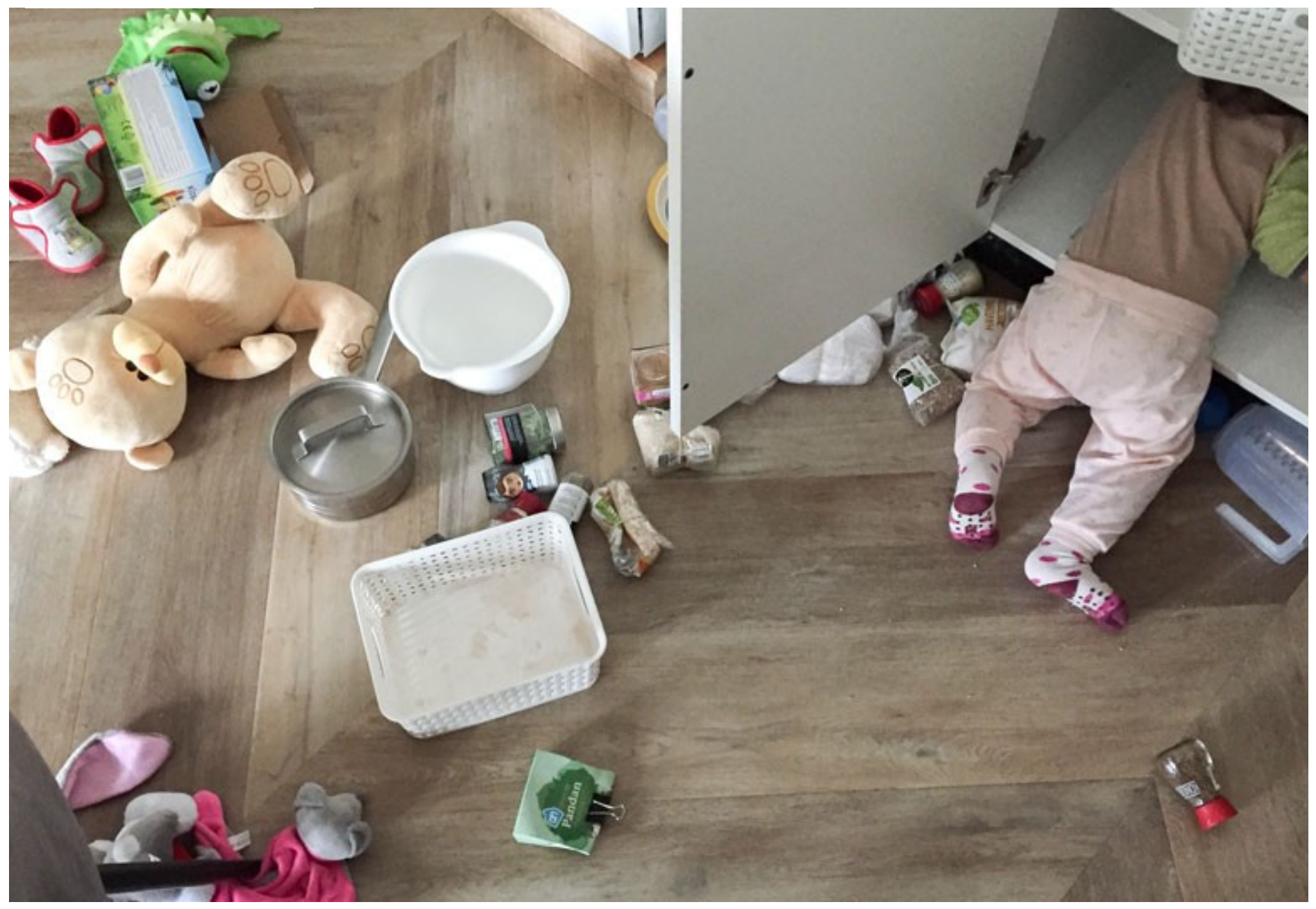

Antica Culina's two-year-old daughter sometimes needs extra supervision during the working day. Credit: Antica Culina

I am the sole carer for my two-year-old daughter. I live far away from my family, and so I depend on a nursery for childcare to get my scientific work done. If I need any extra help - to go to a conference or during an emergency - my parents visit from Croatia. 
But in March, two days before institutions, nurseries and borders closed because of COVID-19, we left the Netherlands, where I work as a research scientist at the Netherlands Institute of Ecology in Wageningen, and flew to Croatia to stay with my parents until the lockdown eased. At the time, it was becoming obvious that things would drastically change, but many were still in denial - I recall a similarly unsettling feeling during my childhood, when the war in Yugoslavia was starting.

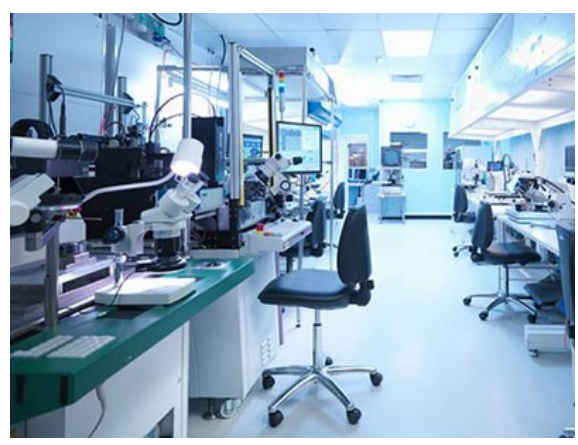

\section{Collection:}

\section{Coronavirus and scientific careers}

My time as a single parent during the pandemic hasn't been easy. The lockdown disrupted my already delicately balanced world. Now, my parents assist with childcare while I try to work. A sense of normality is slowly returning, and we will soon return to the Netherlands.

Here are some steps I've taken to deal with my situation while in Croatia.

\section{Take time to cope with the stress}

At first, I struggled to get down to work. Often, I'd open my laptop only to stare at the transmission-rate graphs and news articles about coronavirus. Soon it became clear that I needed time to adjust to this new way of life and to process

the stress that the situation was causing. I gave myself a couple of weeks (from late March to early April) away from work to try to decompress and to focus on my family, and I made sure I didn't feel guilty about it.

I try to actively enjoy my work tasks rather than just 'doing' them. I find that when my career advancement is on the line, I feel a pressure to finish projects on time and to be productive every day. Often, like many scientists, that pressure means I find myself stressed or on autopilot, rather than enjoying my work. The pandemic made me realize I had other bigger issues to worry about, and so I made sure I reminded myself that I do a job that I like, and to enjoy the excitement of thinking about problems and the ways to solve them.

I set aside at least ten minutes every day to engage in a relaxing activity - for me, that's playing the piano. That ten-minute joyful period was a powerful, restful habit to get into.

\section{Prioritize and set up daily goals}

When the lockdown started I had several deadlines approaching, alongside other research activities I wanted to maintain. Generally, I prioritize tasks on the basis of the urgency and on how many people depend on me.

Recently, I've also prioritized work according to the amount of enjoyment I get from it. For example, I had two urgent manuscript revisions in April, yet I decided to do only one (the one with a later deadline), only because I found the subject more exciting. For the other revision, I asked for an extension, giving my reasons for this request. 
Every morning, I set two types of goal. First, there are easy goals, which I can definitely manage (for example, to finish a set of figures). And then there are achievable goals, which are something I will manage if everything works perfectly and if my daughter decides to be very independent that day or my parents can look after her. If I achieve these, I am proud of myself. If the more difficult task isn't achieved, at least I have my easy tasks done, and can end the day with some sense of positivity.

\section{nature careers}

\section{Tips from Nature}

Careers on

managing time and childcare during the coronavirus

pandemic

\section{Connect with those in a similar situation}

I am a member of a Facebook group for academic single parents, and their support has been invaluable during the pandemic - I get ideas on how to organize myself and my work better. Most importantly, the group has made me to realize that my struggles are shared by many others. This group is private, so I won't share it here, but I recommend others in my situation seriously consider seeking out communities so they don't feel alone and can get help, advice and support from others.

\section{Be flexible and open, and ask for support}

There's no point in sticking to a plan that turns out not to work or that no longer meets your priorities. At the start of the pandemic, my plan was to keep family hours and work

hours completely separate, but I soon realized this would be completely impossible. For example, while I do my data analysis, I'm often required to help wrap various dolls in blankets. My daughter is a regular attendee at our Zoom lab calls and other meetings. Work and family can and do mix - and that is OK. My data are analysed and all the dolls are cosy.

I've found it very important to be as open as possible about my situation - many of my colleagues already know that I am a sole parent, and my institution was very supportive even before the coronavirus.

During the pandemic I have tried to talk about my situation more and share how I'm coping with it, both among colleagues and in the wider scientific community. I am learning not to feel that my sole-parent life will be interpreted as a weakness or an excuse, but rather as a sign of strength. I hope I can increase the awareness of the issues single parents face in academia.

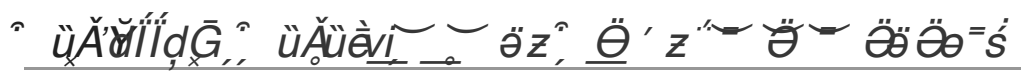

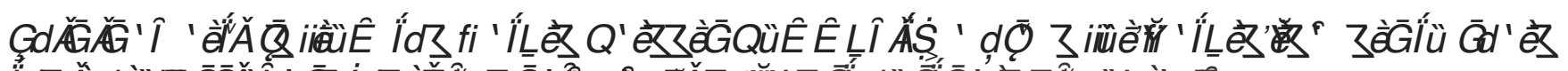

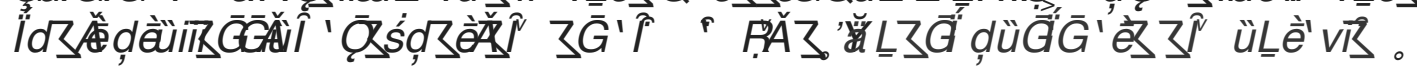


